\title{
Solubilidade e Degradabilidade Ruminal do Amido de Diferentes Alimentos
}

\section{Lucia Maria Zeoula ${ }^{1^{*}}$, Adriana de Souza Martins ${ }^{2}$, Ivanor Nunes do Prado ${ }^{1^{*}}$, Claudete Regina Alcalde ${ }^{1}$, Antonio Ferriani Branco ${ }^{1 *}$, Geraldo Tadeu dos Santos ${ }^{1 *}$}

\begin{abstract}
RESUMO - A solubilidade do amido em solução tampão de bicarbonato-fosfato (AMST) e a degradação ruminal do amido de alguns alimentos pela técnica in situ, usando três vacas Holandesa, foram determinadas neste estudo. Os alimentos foram moídos em peneira com crivo de $2 \mathrm{~mm}$ para os concentrados e $5 \mathrm{~mm}$ para os volumosos e incubados em sacos de náilon (53 micra). Os teores de amido de milho, sorgo, raspa de mandioca, farelo de trigo, triticale, silagem de milho, silagem de sorgo, farelo de soja, farelo de algodão e da polpa cítrica foram, respectivamente, 79,3;83,4;91,4;49,1;65,9;31,6;16,1;5,5; 5,5; e 8,4\% e os teores de AMST, 13,4; 10,7; 14,0; 0,7;20,8; 18,$1 ; 27,0 ; 18,4 ; 68,1 ;$ e $63,3 \%$. A degradação efetiva (DE) do amido foi corrigida (DEc) para as perdas de pequenas partículas que ocorrem no processo de lavagem dos sacos, usando os valores AMST. O milho, o sorgo, a raspa de mandioca, o farelo de trigo e o triticale apresentaram valores de DE do amido de 57,8; 67,5; 79,1; 98,8; e 98,4\% e DEc, de 55,0; 39,5; 62,7; 90,3; e 91,9\% respectivamente. Os valores observados para a DE e DEc diferiram apenas para o sorgo e a raspa de mandioca.
\end{abstract}

Palavras-chave: amido, degradabilidade ruminal, farelo de trigo, milho, raspa de mandioca, solubilidade, sorgo, triticale

\section{Ruminal Solubility and Degradability of Starch of Different Feeds}

\begin{abstract}
The starch solubility in bicarbonate-phosphate buffer (SSB) and the ruminal degradability of starch from some feed by the in situ technique, using three Holstein cows, were evaluated in this study. The feeds were ground through a 2-mm screen for the concentrate and a 5 -mm screen for forage and incubated using nylon bag (53mm). The starch concentration in corn, sorghum, cassava scraping, wheat bran, triticale, corn silage, sorghum silage, soybean meal, cottonseed meal and citrus pulp were: 79.3, 83.4, 91.4, 49.1, 65.9, 31.6, 16.1, 5.5, 5.5, and 8.4\%, respectively, and SSB were 13.4, 10.7, 14.0, 0.7, 20.8, 18.1, 27.0, 18.4, 68.1 and 63.3\%, respectively. The effective degradability (ED) of starch was corrected (EDc) for loss of small particles during the washing process of the nylon bags using SSB values. The corn, sorghum, cassava root, wheat bran, triticale presented starch ED values of 57.8, 67.5, 79.1, 98.8, and 98.4\% and EDc of: 55.5, $39.5,62.7,90.3$, and $91.9 \%$ respectively. The observed values for ED and EDc were different only for sorghum and cassava root.
\end{abstract}

Key Words: starch, ruminal degradability, wheat bran, corn, cassava root, solubility, sorghum, triticale

\section{Introdução}

O amido - principal componente de muitos grãos de leguminosas - representa 70 a $80 \%$ da composição dos grãos de cereais e está presente nas raízes e nos tubérculos. O amido é um polissacarídeo heterogêneo, composto de dois polímeros de glicose: a amilose e a amilopectina. A amilose é uma molécula linear com 900 a 3000 unidades de D-glicose unidas por ligações $\alpha-1,4$. A amilopectina, molécula mais abundante nos diferentes tipos de amido, é um polímero maior, altamente ramificado, com, em média, $10^{4}-10^{6}$ unidades de D-glicose unidas por ligações $\alpha-1,4$ e nos pontos de ramificação unidas por ligações $\alpha-1,6$, as quais ocorrem a cada 20 - 25 unidades de glicose (FRENCH, 1973; GUILBOT e MERCIER, 1985). Estes polímeros de glicose são, em parte, responsá- veis pelas diferentes taxas de digestão do amido.

A solubilidade do amido tem sido muito discutida e ainda apresenta-se como desafio para os cientistas (FRENCH, 1973). Revisando a literatura, ALCALDE (1997) concluiu que não se conhece quantitativamente a real existência de uma fração solúvel do amido. Maltose, maltotriose e oligossacarídeos são altamente solúveis em água e, de fato, a maltotriose e os oligossacarídeos nunca foram induzidos à cristalização. Entretanto, compostos como a maltononaose podem tornar-se higroscópicos, sendo capazes de “cristalizar", não como cristais individuais, mas como microcristais ou cristais micelares (FRENCH, 1973). Ainda segundo este autor, conforme o alongamento da cadeia de amido, dentro de um limite que varia entre 70 e 150 unidades de glicose, o material torna-se insolúvel em água, sendo difícil ou impossível dissolvê- 
lo sem o uso de agentes químicos. Para compostos com 500 unidades de glicose ou mais, a amilose pode ser dissolvida somente pelo aquecimento em água. A solubilidade do amido é eficientemente obtida pela destruição da regularidade da cadeia de amilose, como, por exemplo, a introdução de alguns pontos ramificados e a modificação química (substituição dos grupos $\mathrm{OH}$ pelo acetato, carboximetil, metil, hidroxietil).

A solubilidade dos nutrientes dos alimentos (em água, solução tampão, saliva artificial, etanol e outros meios) tem apresentado alta correlação com a degradabilidade no rúmen (CRAWFORD et al., 1978).

Nos estudos de degradabilidade ruminal, pela técnica in situ, verifica-se que os valores obtidos no tempo zero, isto é, a fração que desaparece no processo de lavagem, normalmente são apresentados como fração solúvel do amido (HERRERASALDANA et al., 1990; NOCEK e TAMINGA, 1991). Todavia, esses autores verificaram que esta fração pode conter outros carboidratos solúveis.

Aman e Hesselman (1984), citados por HERRERASALDANA et al. (1990), encontraram teores de açúcares solúveis (glicose, frutose, sacarose e frutosanas) e polissacarídeos solúveis não amiláceos (contendo arabinose, xilose, manose, galactose, glicose e ácidos urônicos) de 1,8; 12,$6 ; 0,1 ; 16,0 ; 3,6 ;$ e 7,7\% na matéria seca, respectivamente, para cevada, aveia e trigo.

Analisando a solubilidade do amido em solução tampão de bicarbonato-fosfato, HERRERASALDANA et al. (1986) encontraram valores de solubilidade de 5,3; 5,3; e 3,7\% do amido total, para cevada, aveia e milho, respectivamente. Esses valores são inferiores aos observados por HERRERASALDANA et al. (1990), que, utilizando a técnica in vitro para determinar a degradabilidade do amido, obtiveram valores para a fração solúvel do amido de $10,6 \%$ para a cevada e de $7,7 \%$ para o milho. As diferenças entre valores observados nos alimentos foram atribuídas à presença de açúcares solúveis e outros polissacarídeos solúveis que não foram excluídos, quando do uso da técnica in vitro. Determinando-se a degradação do amido pela técnica in situ, HERRERA-SALDANA et al. (1990) observaram que a fração solúvel do amido foram de 21,0; 78,2; 66,2; e 96,6\%, para milho, trigo, cevada, e aveia, respectivamente, e concluíram que o tamanho da partícula dos alimentos incubados $(1 \mathrm{~mm})$ pode explicar os altos valores da fração solúvel, em função das perdas no processo de lavagem.

Segundo NOCEK (1997), a maior limitação na determinação da solubilidade de carboidratos consiste na obtenção de uma técnica segura que possa quantificar as várias frações (amido, açúcares), potencialmente digestíveis no rúmen, em diferentes alimentos.

A avaliação de dietas para bovinos pelo sistema de carboidrato e proteína líquidos (CNCPS), desenvolvido pela Universidade de Cornell, classificou os carboidratos de acordo com suas taxas de degradação, sendo que para a fração correspondente aos açúcares, considerada solúvel em água, se estimou taxa de degradação em torno de $300 \% / \mathrm{h}$ e para fração corresponde ao amido e a pectina, taxa de degradação que variou de 3 a 80\%/h (SNIFFEN et al., 1992).

Segundo VAN SOEST (1994), o amido tem alta digestibilidade, todavia, a extensão da digestão do amido no rúmen pode ser influenciada pelos seguintes fatores: endosperma (córneo versus farináceo), processamento do grão, nível de ingestão de amido, interação proteína e amido, integridade celular e pela presença de inibidores. Grande variação na digestibilidade do amido de diferentes alimentos tem sido relatada; em geral, o amido presente nos cereais foi mais facilmente digerido que o de raízes e tubérculos, enquanto o amido das leguminosas apresentou digestibilidade intermediária (ROONEY e PFLUGFELDER, 1986). Segundo esses autores, a digestibilidade do amido foi, em geral, inversamente proporcional ao conteúdo de amilose. Para McALLISTER et al. (1993), o carboidrato estrutural (cutícula) do grão e a matriz protéica dos grânulos de amido constituem os principais fatores responsáveis por diferenças na digestibilidade entre as fontes de amido.

Devido à escassez de informações sobre a fração solúvel do amido dos alimentos e considerando sua influência na determinação da cinética de degradação ruminal do amido, este trabalho teve por objetivo determinar a solubilidade em solução tampão e a degradação ruminal do amido de alguns alimentos, pela técnica de degradação in situ.

\section{Material e Métodos}

O experimento foi conduzido na Fazenda Experimental e no Laboratório de Nutrição Animal da Universidade Estadual de Maringá (UEM).

A solubilidade do amido do milho, do sorgo, da raspa de mandioca, do farelo de trigo, do triticale, do farelo de soja, da polpa cítrica, do farelo de algodão, da silagem de milho e da silagem de sorgo foi obtida pela incubação destes alimentos em solução tampão, segundo HERRERA-SALDANA et al. (1986), com pequenas modificações. Amostras contendo cinco 
gramas de cada alimento foram incubadas em $100 \mathrm{~mL}$ de solução tampão (pH 6,8) de bicarbonato de sódio e fosfato monobásico de potássio e permaneceram em solução por 45 min sob agitação. Em seguida, cada solução foi filtrada e o resíduo foi transferido para um vidro-relógio e levado para estufa à $55^{\circ} \mathrm{C}$ por dois dias. Após este procedimento, foi feita a análise do amido do resíduo e do alimento, sendo a solubilidade obtida por diferença.

A degradabilidade ruminal do amido do milho, do sorgo, da raspa de mandioca, do farelo de trigo e do triticale foi determinada pela técnica in situ utilizando-se três vacas Holandesa, secas e não-gestantes com peso vivo médio aproximado de $500 \mathrm{~kg}$. Cada animal recebeu $3 \mathrm{~kg}$ de ração concentrada $(20,1 \%$ de PB e $81,1 \%$ de NDT) e $22 \mathrm{~kg}$ de silagem de milho por dia. A composição química e percentual da ração fornecida encontra-se na Tabela 1 .

Os grãos de cereais foram moídos em peneira com crivo de $2 \mathrm{~mm}$, exceto a raspa de mandioca, que foi moída em peneira com crivo de $5 \mathrm{~mm}$, pois apresentou partículas muito finas quando moída a $2 \mathrm{~mm}$. Posteriormente, foram incubados individualmente em sacos de náilon (53 micra), com dimensões de 10 x 17 $\mathrm{cm}$, nos seguintes tempos, em ordem decrescente: 48 , $24,20,16,12,8,6,4,2 \mathrm{~h}$. Foram incubados 5,5 gramas de amostra (base na matéria seca), em triplicada. Os sacos relativos ao tempo $0 \mathrm{~h}$ foram lavados com os demais sacos, em máquina de lavar roupa por $45 \mathrm{~min}$, e representaram a fração solúvel do amido.

Os dados sobre o desaparecimento do amido foram ajustados para uma regressão não-linear. A degradabilidade potencial do amido foi calculada segundo o modelo matemático proposto por MEHREZ e ORSKOV (1977):

$$
\mathrm{DP}=\mathrm{a}+\mathrm{b}\left(1-\exp ^{-\mathrm{ct}}\right)
$$

em que DP (\%) é degradabilidade potencial; a, fração solúvel; $b$, fração potencialmente degradável; c, taxa constante de degradação da fração b; e t, tempo de incubação.

A degradabilidade efetiva foi calculada segundo o modelo proposto por ORSKOV e McDONALD (1979):

$$
\operatorname{DE}(\%)=\mathrm{a}+\left(\left(\mathrm{b}^{*} \mathrm{c}\right) /(\mathrm{c}+\mathrm{k})\right)
$$

em que DE é degradabilidade efetiva e k, taxa estimada de passagem de sólidos no rúmen $(5 \% / \mathrm{h})$.

A degradabilidade efetiva foi corrigida para as perdas de pequenas partículas no tempo zero, utilizando a equação proposta por Weisbjerg et al. (1990), citados por HUNTINGTON e GIVENS (1997), com pequena modificação, utilizando-se os valores de solubilidade em solução tampão:

$$
\mathrm{DEc}=\mathrm{ws}+[((100-\mathrm{ws}) / 100-\mathrm{a}) \mathrm{x} \mathrm{DE}-\mathrm{a}]
$$

em que DEc é degradabilidade efetiva corrigida; ws, fração solúvel em solução tampão; a, fração solúvel (obtida por intermédio da lavagem dos sacos - tempo zero); e DE, degradabilidade efetiva.

$\mathrm{O}$ teor de matéria seca das amostras foi obtido em estufa a $105^{\circ} \mathrm{C}$. A determinação do amido foi feita utilizando-se o método enzimático descrito por POORE et al. (1989), seguindo as adaptações de PEREIRA e ROSSI (1995).

A análise estatística para DE e DEc foi feita por meio do Sistema Computacional SAEG empregandose o seguinte modelo:

$$
\mathrm{Y}_{\mathrm{ijk}}=\mathrm{m}+\mathrm{A}_{\mathrm{i}}+\mathrm{D}_{\mathrm{j}}+\mathrm{AD}_{\mathrm{ij}}+\mathrm{e}_{\mathrm{ijk}}
$$

em que $Y_{i j k}$ é observação $\mathrm{K}$, para a fonte de amido i e degradabilidade efetiva $j ; A_{i}$, efeito da fonte de amido $\mathrm{i} ; \mathrm{D}_{\mathrm{j}}$, efeito da correção ou não para a degradabilidade efetiva $\mathrm{j} ; \mathrm{AD}_{\mathrm{ij}}$, efeito da interação entre fonte de amido e DE e Dec; e $\mathrm{e}_{\mathrm{ijk}}$, erro aleatório associado a cada observação.

Quando houve interação entre fonte de amido e DE e DEc, procedeu-se ao desdobramento da interação, analisando-se o efeito da DE corrigida ou não dentro de fonte de amido.

\section{Resultados e Discussão}

Os teores de matéria seca (MS), amido (AM) e amido solúvel em solução tampão (AMST) de milho, sorgo, raspa de mandioca, triticale, farelo de trigo, polpa cítrica, farelo de soja, farelo de algodão, silagens de milho e sorgo encontram-se na Tabela 2.

\section{Teor de amido dos alimentos}

O teor de AM observado para o milho (79,3\%) encontra-se próximos dos valores de 75,7 $\pm 3 \%$ e 76,1 $\pm 8,8 \%$ encontrados por HERRERA-SALDANA et al. (1990) e PATTON (1994), respectivamente, e superior aos valores observados por MERTENS (1992), SMET et al. (1995) e PEREIRA et al. (1997), que foram 71,9 e 71,0 e 65,1\%, respectivamente.

O sorgo apresentou teor de amido $(83,4 \%)$ dentro da concentração observada por NOCEK e TAMMINGA (1991), de 66,7 a $84,1 \%$, porém superior aos encontrados por HIBBERG et al. (1982), PATTON (1994), SMET et al. (1995) e ROSSI et al. (1997), que variaram de 61 a $79 \%$.

O teor de amido da raspa de mandioca $(91,4 \%)$ foi superior ao relatado por NOCEK e TAMMINGA (1991) e SMET et al. (1995), 74,5 e 71,6\%, respecti- 
ZEOULA et al.

Tabela 1- Composição química (\%MS) dos ingredientes ${ }^{1}$ e composição da ração (\%)

Table 1 - Chemical composition (\% DM) of the ingredients and diet composition (\%)

\begin{tabular}{|c|c|c|c|c|c|}
\hline Alimento & MS & PB & FDN & EB(Mcal/kg) & Ração (\%) \\
\hline Feed & $D M$ & $C P$ & $N D F$ & $G E$ & Diet \\
\hline Milho & 87,45 & 8,30 & 11,00 & 4,30 & 1,5 \\
\hline Corn & & & & & \\
\hline $\begin{array}{l}\text { Sorgo } \\
\text { Sorghum }\end{array}$ & 89,40 & 9,05 & 14,78 & 4,35 & 4,1 \\
\hline Triticale & 88,86 & 14,46 & 15,79 & 4,33 & 2,0 \\
\hline $\begin{array}{l}\text { Triticale } \\
\text { Farelo de soja } \\
\text { Soybean meal }\end{array}$ & 87,99 & 48,74 & 16,99 & 4,61 & 1,1 \\
\hline $\begin{array}{l}\text { F. de carne e ossos } \\
\text { Meat and bone meal }\end{array}$ & 87,45 & 36,46 & - & 2,58 & 2,0 \\
\hline $\begin{array}{l}\text { Levedura } \\
\text { Yeast }\end{array}$ & 93,38 & 28,01 & 2,20 & 4,03 & 0,9 \\
\hline $\begin{array}{l}\text { Sal } \\
\text { Salt }\end{array}$ & - & - & - & - & 0,2 \\
\hline $\begin{array}{l}\text { Silagem de milho } \\
\text { Corn silage }\end{array}$ & 33,30 & 7,85 & 45,78 & 4,10 & 88,1 \\
\hline
\end{tabular}

Tabela 2 - Teor de matéria seca(MS), amido (AM) e amido solúvel em solução tampão bicarbonatofosfato (AMST) dos alimentos

Table 2 - Dry matter, starch (\% DM) and bicarbonato-phosphate buffer soluble starch of the feeds

\begin{tabular}{|c|c|c|c|}
\hline Alimento & MS (\%) & AM (\% MS) & $\begin{array}{c}\text { AMST ( } \% \text { amido) } \\
\text { (affor }\end{array}$ \\
\hline Feed & $D M$ & Starch $(\% D M)$ & Buffer soluble starch (\% starch) \\
\hline Milho & 87,45 & 79,32 & 13,1 \\
\hline Corn & & & \\
\hline $\begin{array}{l}\text { Sorgo } \\
\text { Sorghum }\end{array}$ & 89,40 & 83,37 & 10,7 \\
\hline $\begin{array}{l}\text { Raspa de mandioca } \\
\text { Cassava root }\end{array}$ & 81,90 & 91,39 & 14,0 \\
\hline $\begin{array}{l}\text { Farelo de trigo } \\
\text { Wheat bran }\end{array}$ & 87,62 & 49,14 & 0,7 \\
\hline $\begin{array}{l}\text { Triticale } \\
\text { Triticale }\end{array}$ & 88,86 & 65,94 & 20,8 \\
\hline $\begin{array}{l}\text { Silagem de milho } \\
\text { Corn silage }\end{array}$ & 33,05 & 31,60 & 18,1 \\
\hline $\begin{array}{l}\text { Silagem de sorgo } \\
\text { Sorghum silage }\end{array}$ & 30,45 & 16,13 & 27,0 \\
\hline $\begin{array}{l}\text { Farelo de soja } \\
\text { Soybean meal }\end{array}$ & 87,08 & 5,50 & 18,4 \\
\hline $\begin{array}{l}\text { Farelo de algodão } \\
\text { Cottonseed meal }\end{array}$ & 89,48 & 5,48 & 68,1 \\
\hline $\begin{array}{l}\text { Polpa cítrica } \\
\text { Citrus pulp }\end{array}$ & 86,17 & 8,44 & 63,3 \\
\hline
\end{tabular}

vamente. ZEOULA (1990) determinou, por meio de hidrólise ácida, o teor de carboidratos totais disponíveis (que incluem mono, di e polissacarídeos, principalmente o amido) para raspa de mandioca, e encontrou o valor de $97,9 \%$.

O farelo de trigo apresentou teor de amido $(49,1 \%)$ superior ao encontrado por NOCEK e TAMMINGA (1991), que foi de 20,8\%.

O triticale - um cereal híbrido, resultado do cruzamento do trigo e centeio - apresentou teor de amido de $65,9 \%$, próximo ao valor de $66,3 \%$, obtido por METAYER et al. (1993). Todavia, segundo esses autores, a composição química do triticale pode variar em função das variedades, do local ou solo em que é cultivado e do ano de cultura.

As silagens de milho e sorgo continham 31,6 e $16,1 \%$ de amido, respectivamente. PEREIRA et al. (1997a) verificaram valor de $27,2 \%$ de amido na silagem de milho com $36 \%$ de grãos, que é inferior ao da presente pesquisa. Porém, o valor obtido encon- 
tra-se dentro da faixa observada por MERTENS (1992) e PATTON (1994) de $27,7 \%$ e $39,4 \pm 9,5 \%$, respectivamente.

Segundo HERRERA-SALDANA et al. (1990), as diferenças observadas na análise de amido dos alimentos são maiores com aumento no conteúdo de celulose, resultado da contaminação da fibra sobre a pequena quantidade de amostra utilizada nas análises ou maior dificuldade de amostragem de alimentos com maior teor de fibra.

O farelo de soja apresentou teor de amido $(5,5 \%)$ muito inferior ao apresentado por HERRERASALDANA et al. (1986), de 27,2\%, e semelhante ao observado por SMET et al. (1995) e superior ao valor encontrado por ROSSI et al. (1997), 2,8\%.

$O$ teor de amido do farelo de algodão $(5,5 \%)$ foi inferior ao observado por HERRERA-SALDANA et al. (1986) de 12,7\% e superior ao apresentado por PEREIRA et al. (1997), que encontraram 0,79\% de amido no farelo de algodão.

A polpa cítrica, um alimento de rápida fermentação no rúmen, apresentou baixo teor de amido $(8,4 \%)$ e, segundo VAN SOEST (1982), apresenta quantidade expressiva de pectina.

Algumas das diferenças entre os valores de amido dos alimentos estudados podem estar relacionadas com a metodologia de análise. Metodologias que empregam a digestão ácida e utilizam reagentes, como de Fehling, podem estar determinando açúcares redutores totais que fazem parte dos carboidratos nãoestruturais e considerando-os como se fossem amido.

Solubilidade do amido dos alimentos em solução de bicarbonato-fosfato $(\mathrm{pH} \quad 6,8)$

Os valores de solubilidade do amido em solução tampão (AMST) do milho, do sorgo, da raspa de mandioca, do farelo de trigo, do triticale, do farelo de soja, da polpa cítrica, do farelo de algodão, da silagem de milho e da silagem de sorgo encontram-se na Tabela 2.

Verificou-se que o milho, o sorgo e a raspa de mandioca apresentaram teores de AMST variando de 10 a 14\%, o triticale apresentou 20,8\% de AMST e o farelo de trigo obteve o menor valor, $0,7 \%$. HERRERA-SALDANA et al. (1986) determinaram a solubilidade do amido do milho, em solução de bicarbonato-fosfato $(\mathrm{pH} 6,8)$, e verificaram valor $3,3 \%$ inferior ao observado no presente trabalho.

Os maiores valores de solubilidade do amido (\% do amido total) foram observados para farelo de algodão $(68,1 \%)$ e polpa cítrica $(63,3 \%)$, porém estes alimentos apresentaram baixos teores de amido, 5,5 e $8,4 \%$, respectivamente. HERRERA-SALDANA et al. (1986) verificaram valores de 12,7 e 33,5\%, respectivamente, para amido no farelo de algodão e AMST, os quais foram inferiores ao presente trabalho. Para o farelo de soja, esses autores encontraram $27,7 \%$ de amido com solubilidade de $26,9 \%$, superiores aos teores de amido (5,5\%) e AMST (18,4\%) observados.

Nas silagens de milho e sorgo, os valores de AMST foram de 18,1 e 27,0\%. A solubilidade parcial do amido das silagens pode ser favorecida pelos ácidos provenientes do processo de fermentação. Segundo VAN SOEST (1994), os ácidos fracos atuam rompendo as pontes de hidrogênio entre as moléculas de glicose, favorecendo a solubilidade do amido.

São poucos os dados de solubilidade do amido disponíveis na literatura. Entretanto, observa-se que a fração solúvel dos carboidratos não-estruturais, principalmente açucares, é muito pequena. $\mathrm{O}$ teor de açúcar contido no milho é baixo e varia de 1 a $2 \%$ (Cone et al., 1989, citados por ALCALDE, 1997; SMET et al., 1995). Os teores de açúcares do sorgo, da mandioca e do trigo obtidos por SMET et al. (1995) foram 0,$7 ; 1,7$; e $2,8 \%$, respectivamente.

\section{Degradabilidade ruminal do amido}

As frações solúvel (a), potencialmente degradável (b), a taxa de degradação da fração "b" (c), a degradabilidade efetiva (DE) e a degradabilidade efetiva corrigida (DEc) do amido de milho, sorgo, raspa de mandioca, triticale e farelo de trigo encontram-se na Tabela 3 .

A fração "a" do amido do milho (18,5\%) foi semelhante à encontrada por PEREIRA et al. (1997b), que foi de $17,5 \%$. O valor desta fração para o sorgo $(52,1 \%)$ mostrou-se alto em comparação ao de $12,1 \%$ obtido por ROSSI et al. (1997).

Os valores da fração "a”, que representa a fração solúvel, obtidos pela lavagem dos sacos sem incubação, observados para o sorgo, a raspa de mandioca e, principalmente, o triticale e farelo de trigo, apresentaram-se elevados e foram muito superiores aos obtidos para o AMST (Tabela 2). Portanto, deduziuse que os elevados valores desta fração ocorreram mais em função da fração perdida no processo de lavagem, que é considerada como fração solúvel do amido. Estas observações encontram apoio nos achados de HUNTINGTON e GIVES (1997), os quais consideram que os valores determinados no tempo zero hora, por meio da lavagem dos sacos sem a incubação no rúmen, contêm dois componentes: (1) 
ZEOULA et al.

Tabela 3 - Fraçào solúvel (a), potencialmente degradável (b), taxa de degradação (c) e degradação efetiva (DE) e corrigida (DEc) do amido para taxa de passagem de $5 \% / h$ dos alimentos

Table 3 - Soluble fraction (a), fraction potentially degradable (b), degradation rate (c) and starch effetive degradability for passage rate of $5 \% / h$ of the feed

\begin{tabular}{|c|c|c|c|c|c|}
\hline Alimento & a & $\mathrm{b}$ & $\mathrm{c}$ & $\mathrm{DE}$ & $\mathrm{DEc}$ \\
\hline Feed & $a$ & $b$ & $c$ & & \\
\hline $\begin{array}{l}\text { Milho } \\
\text { Corn }\end{array}$ & 18,4 & 81,5 & 0,047 & $57,8^{\mathrm{a}}$ & $55,0^{\mathrm{a}}$ \\
\hline $\begin{array}{l}\text { Sorgo } \\
\text { Sorghum }\end{array}$ & 52,1 & 38,1 & 0,034 & $67,5^{\mathrm{a}}$ & $39,5^{\mathrm{b}}$ \\
\hline $\begin{array}{l}\text { R. mandioca } \\
\text { Cassava root }\end{array}$ & 52,0 & 47,3 & 0,067 & $79,1^{\mathrm{a}}$ & $62,7^{b}$ \\
\hline $\begin{array}{l}\text { Triticale } \\
\text { Triticale }\end{array}$ & 84,6 & 15,1 & 0,507 & $98,4^{\mathrm{a}}$ & $91,9^{\mathrm{a}}$ \\
\hline $\begin{array}{l}\text { Farelo de trigo } \\
\text { Wheat bran }\end{array}$ & 87,3 & 12,6 & 0,514 & $98,8^{\mathrm{a}}$ & $90,3^{\mathrm{a}}$ \\
\hline
\end{tabular}

Médias na linha, seguidas de letras diferentes são diferentes $(P<0,05)$ pelo teste $F$.

Means, within a row, followed by different letters are different $(P<.05)$ by $F$ test.

perdas da fração solúvel e (2) perdas de pequenas partículas. Outros fatores como porosidade do saco de náilon, granulometria do alimento e origem dos grãos podem influir na determinação da fração "a", comprometendo as frações "b" e "c" e, conseqüentemente, a degradabilidade do amido (HERRERASALDANA, 1990).

A taxa de degradação "c" do amido do milho $(4,7 \% / \mathrm{h})$ foi inferior aos 10 a $20 \% / \mathrm{h}$ preconizados pelo NRC (1996) para taxa de digestão da fração "b1" (amido e pectina). Entretanto, MERTENS (1992) estimou que a taxa de degradação do amido do milho moído está na faixa de 6 a 14\%/h, enquanto PEREIRA et al. (1997) encontraram valor de $3,8 \% / \mathrm{h}$ para a taxa de degradação do amido do milho.

Para o sorgo e a raspa de mandioca, os valores da taxa de degradação da fração "b" foram de 3,4 e 6,7\%/ $\mathrm{h}$, respectivamente, e inferiores aos divulgados pelo NRC (1996), de $12 \% / \mathrm{h}$ para o sorgo e de $40 \%$ /h para tapioca. Porém a taxa de degradação de $40 \% / \mathrm{h}$ para o farelo de trigo, citado pelo NRC (1996), é inferior ao observado neste estudo $(51,4 \% / \mathrm{h})$. Considerando-se as informações obtidas no presente estudo, pode-se sugerir que as taxas de degradação da fração "b" podem estar comprometidas, principalmente, dos alimentos que apresentaram alto valor da fração "a" e, conseqüentemente, baixo valor da fração " $b$ ".

Nos resultados do presente experimento observou-se interação da fonte de amido e DE e DEc apenas para o sorgo e a raspa de mandioca. HUNTINGTON e GIVENS (1997) verificaram que a DE e DE corrigidas por intermédio da determinação da solubilidade foram significativamente diferentes, para a matéria seca do feno, do farelo de soja e da farinha de peixe.

Para o milho, a diferença entre o valor da fração solúvel do amido obtido pela lavagem dos sacos $(18,4 \%)$ e da fração solúvel obtida em solução tampão $(13,1 \%)$ não foi tão discrepante como quando se compararam os dois valores da referida fração para os demais alimentos estudados, não havendo para este alimento diferença significativa entre a DE e DEc do amido. O valor médio obtido $(56,4 \%)$ foi próximo ao valor de DE do amido do milho $(57,3 \%)$ encontrado por MORON et al. (1996).

Com relação ao amido do sorgo, houve diferença $(\mathrm{P}<0,05)$ entre DE e DEc. O valor observado para a DE do amido do sorgo $(67,5 \%)$, para taxa de passagem de $5 \% / \mathrm{h}$, foi superior aos encontrados por NOCEK e TAMMINGA (1991) de 54,2\%, para taxa de passagem de $8 \% / \mathrm{h}$, e MORON et al. (1996) de 48,6\%. Todavia, a DEc do amido do sorgo apresentou valor inferior (39,5\%). Embora, os grânulos de amido do sorgo e milho sejam muito semelhantes quanto a tamanho, forma e composição, o sorgo foi menos digestível que o milho e, para ROONEY e PFLUGFELDER (1986), a principal diferença está relacionada à maior proporção de endosperma periférico no sorgo, o qual é extremamente denso, duro e resistente à digestão. Desse modo, considerando-se os valores observados para a DE e DEc do amido do sorgo, pode-se destacar que a DEc está mais condizente com as observações citadas, uma vez que apresenta valor inferior ao observado para a $\mathrm{DE}$ do amido do milho.

Houve diferença $(\mathrm{P}<0,05)$ entre DE e DEc do amido da raspa de mandioca. Semelhantemente ao sorgo, pode-se sugerir que estas diferenças sejam atribuídas ao elevado valor da fração "a" do amido, 
904 Rev. bras. zootec.

quando a mesma é obtida pelo processo de lavagem dos sacos, se comparada aos dados de solubilidade em solução tampão. $O$ desaparecimento da matéria seca observado no tempo de zero foi $48 \%$ para o sorgo e $57 \%$ para a raspa de mandioca. Estes valores refletem perdas de partículas ocorridas em função da moagem dos alimentos que superestimou a fração solúvel. O valor de DEc do amido da raspa de mandioca $(62,7 \%)$, para taxa de passagem de $5 \% / \mathrm{h}$, foi inferior ao valor relatado para a tapioca por NOCEK e TAMMINGA (1991) de 82,7\%, para taxa de passagem de $8 \% / \mathrm{h}$. Todavia, ZEOULA et al. (1998) verificaram que a DE do amido da raspa de mandioca amassada variou de 80,6 a $57,1 \%$ para taxas de passagem de sólidos de 2 e $8 \% / \mathrm{h}$, respectivamente. Vale salientar que esses autores não apresentaram a DE para taxa de passagem de $5 \%$. No entanto, para esta taxa de passagem, a DE do amido da raspa de mandioca amassada estaria próximo ao valor de DEc do presente trabalho. Ainda, esses autores. observaram que a fração solúvel (a) do amido da mandioca amassada foi de $23,1 \%$, valor mais próximo ao de AMST (14,0\%) que o obtido no processo de lavagem dos sacos $(52,0 \%)$.

$\mathrm{O}$ farelo de trigo e o triticale não apresentaram diferenças entre a DE e DEc, sendo observados valores médios de 94,5 e 95,2\%, respectivamente. Todavia, verifica-se que os valores observados para a solubilidade do amido (AMST) destes alimentos e os observados para fração "a", obtido pelo método in situ, são muito discrepantes, o que resultou em diferenças de 6,5 e 8,5 unidades percentuais entre DE e DEc, respectivamente, para o triticale e farelo de trigo. Também foi observado, no tempo zero, que o desaparecimento da matéria seca (fração "a") foi de 70,0 e $62,0 \%$, respectivamente, para o triticale e o farelo de trigo. Considerando que o amido representa de 50 a $70 \%$ desses alimentos, pode-se sugerir que o desaparecimentoda matéria secaéo principal determinante desta fração. $\mathrm{O}$ farelo de trigo e o triticale apresentaram alta degradabilidade ruminal entre os grãos de cereais estudados e, portanto, são mais facilmente digeridos que o milho e o sorgo, ainda que estes últimos apresentem maior conteúdo de amido e açúcares (SMET et al., 1995).

Quanto ao tamanho da partícula dos alimentos $(2 \mathrm{~mm}$ para os grãos de cereais e $5 \mathrm{~mm}$ para a raspa de mandioca) avaliados pela técnica in situ, para estimativas da degradabilidade ruminal do amido, verificaram-se perdas de partículas, resultando em valores elevados da fração "a". Sugere-se que as amostras sejam apenas fragmentadas, e não moídas.

\section{Conclusões}

Pelos resultados observados nesta pesquisa, podese concluir que a fração solúvel do amido obtida pela lavagem dos sacos, no tempo zero, pode ser superestimada, devido à ocorrência de perdas de partículas do interior do saco, influenciando, desse modo, os valores de degradabilidade ruminal dos alimentos e comprometendo os parâmetros " $\mathrm{b}$ " e "c".

O tamanho de partículas dos grãos de cereais e raízes tem efeito nos estudos de degradabilidade ruminal do amido.

\section{Referências Bibliográficas}

ALCALDE, C. R. Avaliação da granulometria ou hidratação do milho através da digestibilidade aparente, degradação ruminal e desempenho de bovinos. Jaboticabal, SP: FCAVJ, 1997. 111 p. Tese (Doutorado em Zootecnia) - Faculdade de Ciências Agrárias e Veterinárias do Campus de Jaboticabal, 1997.

CRAWFORD JR., R.J., HOOVER, W.H., SNIFFER, C.J. et al. 1978. Degradation of feedstuffs nitrogen in the rumen vs nitrogen solubility in three solvents. J. Anim. Sci., 46(6): 1768-1775.

FRENCH, D. 1973. Chemical and physical properties of starch. J. Anim. Sci, 37(4):1048-1061.

GUILBOT, A., MERCIER, C. 1985. Starch. In: ASPINALL, G.D. The polysaccharides. New York: Academic Press, 3:229-285.

HERRERA-SALDANA, R.E., HUBER, J.T., POORE, M.H. 1990. Dry matter, crude protein and starch degradability of five cereal grains. J. Dairy Sci., 73(9):2386-2393.

HERRERA-SALDANA, R.E., HUBER, J.T, SWINGLE, R.S. 1986. Protein and starch solubility and degradability of several common feedstuffs. J. Dairy Sci., 69 (suppl.1):141(abstr.).

HIBBERG, C.A., WAGNER, D.G., SCHEMM, R.L. et al. 1982. Nutritive caracteristics of different varieties of sorghum and corn grains. J. Anim. Sci., 55(3):665-672.

HUNTINGTON, J.A., GIVENS, D.I. 1997. Studies on in situ degradation of feeds in the rumen: 1 . Effect of species, bag mobility and incubation sequence on dry matter disappearance. Anim. Feed Sci. and Techn., 64:227-241.

McALLISTER, T.A., PHILLIPE, R. C., RODE, L.M. et al. 1993. Effect of the protein matrix on the digestion of cereal grains by ruminal microorganisms. J. Anim. Sci., 71(1):205-212.

MEHREZ, A.Z., ORSKOV, E.R. 1977. A study of the artificial fiber bag tecnique for determining the digestibility of feeds in the rumen. J. Agric. Sci., 88:645-650.

MERTENS, D.R. Nonstrutural and strutural carboydrates. In: PROCEEDINGS LARGE DAIRY HERD MANAGEMENT. p. 219-235, 1992.

METAYER, J.P., GROSJEAN, F., CASTAING, J. 1993. Study of variability in French cereals. Anim. Feed Sci. and Techn., 43:87-108.

MORON, I.R., TEIXEIRA, J.V., OLIVEIRA, A.L. et al. Cinética de digestão ruminal do amido dos grãos de milho e sorgo submetidos a diferentes formas de processamento, em vacas da raça Holandesa e Jersey. In: REUNIÃO ANUAL DA SOCIEDADE BRASILEIRA DE ZOOTECNIA, Fortaleza, 
1996. Anais...Fortaleza, v.3, p.162, 1996.

NATIONAL RESEARCH COUNCIL - NRC. 1996. Nutrient requeriments of beef cattle. 7.ed., Washington, National Academy Press, 242p.

NOCEK, J.E. In situ e outros métodos para estimar a proteína ruminal e a digestibilidade da energia: Revisão. In: SIMPÓSIO INTERNACIONAL DE DIGESTIBILIDADE EM RUMINANTES, 1997, Lavras, MG. Anais... Lavras: UFLA FAEPE, 327p, 1997.

NOCEK, J.E., TAMMINGA, S. 1991. Site of digestion of starch in the gastrointestinal tract of dairy cows and its effect on milk yield and composition. J. Dairy Sci., 74(10):3598-3629.

ORSKOV, E.R., McDONALD, I. 1979. The estimation of protein degradability in the rumen from incubation measurements weighted according to rate of passage. $J$. Agric. Sci., 92(6):499-503.

PATTON, R.S. 1994. Complexities of soluble carboydrate metabolism in ruminants. Feedstuffs, 66(6):1624-1633.

PEREIRA, J.R.A., BOSE, M.L.V., BOIN, C. 1997a. Avaliação das sub-frações dos carboidratos e das proteínas, usando a metodologia do CNCPS e in situ, com bovinos da raça Nelore. 1. Silagem de milho. R. Soc. Bras. Zootec., 26(4):832-837.

PEREIRA, J.R.A., BOSE, M.L.V., BOIN, C. 1997b. Avaliação das sub-frações dos carboidratos e das proteínas, usando a metodologia do CNCPS e in situ, com bovinos da raça Nelore. 2.Milho e farelo de algodão. R. Soc. Bras. Zootec., 26(4):838-843.

PEREIRA, J.R.A., ROSSI JR., P. 1995. Manual prático de avaliação nutricional de alimentos. Piracicaba: FEALQ, 25p.

POORE, M.H., ECK, T.P., SWINGLE, R.S. et al. Total starch and relative starch avaliability of grains. In: BIENAL CONFERENCE ON RUMEN FUNCTION, 1989, Chicago. Abstracts... Chicago, v.20, p.35.

ROSSI JR., P., BOSE, M.L.V., BOIN, C. et al. 1997. Degradabilidade ruminal do amido da silagem de milho, farelo de soja e sorgo em grão, em bovinos da raça Nelore. $R$. Soc. Bras. Zootec., 26(2):417-422.
ROONEY, L.W., PFLUGFELDER, R.L. 1986. Factors afecting starch digestibility with special emphasis on sorghum and corn. J. Anim. Sci., 63:1607-1623.

SMET, A.M., BOEVER, J.L., BRABANDER, D.L. et al. 1997. Investigation of dry matter degradation and acidotic effect of some feedstuffs by means of in sacco and in vitro incubations. Anim. Feed Sci. and Techn., 64:227-241.

SNIFFEN, C.J., O CONNOR, J.D., VAN SOEST, P.J. et al. 1992. A net carbohydrates and protein system for evaluating cattle diets: 11. Carbohydrates and protein avaliability. $J$. Anim. Sci., 70:3562-3577.

VAN SOEST, P.J. 1994. Nutritional ecology of the ruminant. 2. ed. New York: Ithaca. 476p.

ZEOULA, L.M. Efeitos da fonte de amido, do processamento e da adição de uréia sobre a fermentação "in vitro" e digestão parcial e total em bovídeos. Viçosa, MG, UFV, 1990. 250p. Tese (Doutorado em Zootecnia) - Universidade Federal de Viçosa, 1990.

ZEOULA, L.M., ALCALDE, C.R., FREGADOLII, F.L. et al. Degradação ruminal de grãos de cereais e da raspa de mandioca amassados. In: REUNIÃO ANUAL DA SOCIEDADE BRASILEIRA DE ZOOTECNIA, 35, Botucatu, 1998. Anais...Botucatu, v.1, p.35-37, 1998.

Recebido em: 08/05/98

Aceito em: 08/03/99 